BMC

Genomics

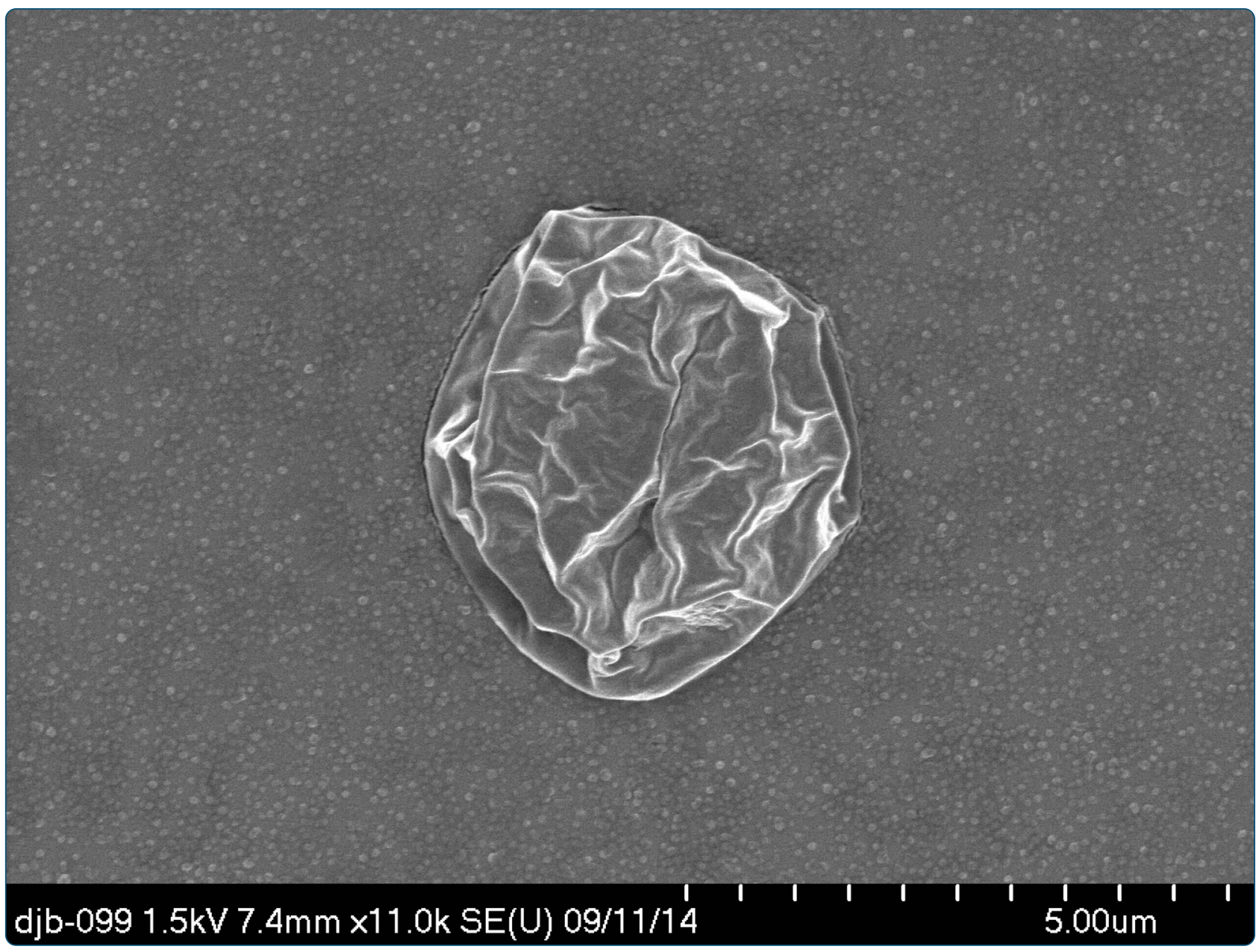

Generation of whole genome sequences of new Cryptosporidium hominis and Cryptosporidium parvum isolates directly from stool samples

Hadfield et al. 


\title{
Generation of whole genome sequences of new Cryptosporidium hominis and Cryptosporidium parvum isolates directly from stool samples
}

\author{
Stephen J. Hadfield ${ }^{1 \dagger}$, Justin A. Pachebat ${ }^{2 \dagger}$, Martin T. Swain ${ }^{2 \dagger}$, Guy Robinson ${ }^{1}$, Simon JS Cameron ${ }^{2}$,
} Jenna Alexander ${ }^{2}$, Matthew J. Hegarty ${ }^{2}$, Kristin Elwin $^{1}$ and Rachel M. Chalmers ${ }^{1 *}$

\begin{abstract}
Background: Whole genome sequencing (WGS) of Cryptosporidium spp. has previously relied on propagation of the parasite in animals to generate enough oocysts from which to extract DNA of sufficient quantity and purity for analysis. We have developed and validated a method for preparation of genomic Cryptosporidium DNA suitable for WGS directly from human stool samples and used it to generate 10 high-quality whole Cryptosporidium genome assemblies. Our method uses a combination of salt flotation, immunomagnetic separation (IMS), and surface sterilisation of oocysts prior to DNA extraction, with subsequent use of the transposome-based Nextera XT kit to generate libraries for sequencing on Illumina platforms. IMS was found to be superior to caesium chloride density centrifugation for purification of oocysts from small volume stool samples and for reducing levels of contaminant DNA.

Results: The IMS-based method was used initially to sequence whole genomes of Cryptosporidium hominis gp60 subtype IbA10G2 and Cryptosporidium parvum gp60 subtype llaA19G1R2 from small amounts of stool left over from diagnostic testing of clinical cases of cryptosporidiosis. The C. parvum isolate was sequenced to a mean depth of 51.8X with reads covering $100 \%$ of the bases of the C. parvum lowa II reference genome (Bioproject PRJNA 15586), while the C. hominis isolate was sequenced to a mean depth of $34.7 \mathrm{X}$ with reads covering $98 \%$ of the bases of the C. hominis TU502 v1 reference genome (Bioproject PRJNA 15585).

The method was then applied to a further 17 stools, successfully generating another eight new whole genome sequences, of which two were C. hominis (gp60 subtypes IbA10G2 and laA14R3) and six C. parvum (gp60 subtypes IlaA15G2R1 from three samples, and one each of IlaA17G1R1, IlaA18G2R1, and IIdA22G1), demonstrating the utility of this method to sequence Cryptosporidium genomes directly from clinical samples. This development is especially important as it reduces the requirement to propagate Cryptosporidium oocysts in animal models prior to genome sequencing.
\end{abstract}

Conclusion: This represents the first report of high-quality whole genome sequencing of Cryptosporidium isolates prepared directly from human stool samples.

Keywords: Whole genome sequencing, Illumina, Nextera XT, Cryptosporidium, Stool, Immunomagnetic separation

\footnotetext{
*Correspondence: Rachel.Chalmers@wales.nhs.uk

Stephen J Hadfield, Justin A Pachebat, Martin T Swain are first joint authors.

${ }^{\dagger}$ Equal contributors

${ }^{1}$ Cryptosporidium Reference Unit, Public Health Wales Microbiology ABM,

Singleton Hospital, Sgeti, Swansea, SA2 8QA, United Kingdom

Full list of author information is available at the end of the article
} 


\section{Background}

Cryptosporidium is a genus of protozoan parasites which are a major cause of gastrointestinal infection worldwide. Symptoms of human cryptosporidiosis include diarrhoea abdominal pain, nausea or vomiting and low grade fever. These are usually self-limiting, albeit after 2 or even 3 weeks, but can be prolonged or invasive and life-threatening in patients with severe T-cell immune-deficiency [1]. Cryptosporidium spp. are also increasingly recognised as an important cause of childhood morbidity and mortality in developing countries [2]. Treatment options are limited, with only one specific licenced therapeutic. Of the 26 Cryptosporidium spp. currently named, Cryptosporidium hominis and Cryptosporidium parvum are the most common causes of cryptosporidiosis in humans globally. Research into the biology of the organism has been partly hampered by the lack of an effective cell culture system for propagation and the limited availability of genomic sequence data, impacting, for example, on progress in understanding the taxonomic position of the protozoan, therapeutic drug discovery, and identification of diagnostic, virulence and subtyping markers.

Whole genome sequences produced using Sanger sequencing techniques, are publically available for single isolates of three species which have historically provided reference genomes for the mainly anthroponotic C. hominis (isolate TU502), the zoonotic C. parvum (isolate IOWA II), and C. muris (isolate RN66) which primarily infects rodents [3, 4]; NCBI BioProjects: PRJNA15585 PRJNA15586, PRJNA32283). Recently, new whole genome sequences have been made available from next generation sequencing (NGS) platforms, providing updated versions of the genome sequences for $C$. hominis TU502 and $C$. parvum IOWA II and new genome sequences for additional isolates: C. hominis UKH1, C. meleagridis UKMEL1 and C. baileyi TAMU-09Q1 (www.cryptoDB.org). The powerful technologies provided by NGS have dramatically reduced the cost and time required for whole genome sequencing, greatly increasing our knowledge of Cryptosporidium spp. by, for example, allowing indepth, high-resolution comparison of isolates and deep sequencing of selected loci for investigation of parasite population variability. However, significant challenges exist for generation of whole genome sequence data, largely because even the most sensitive sample preparation kit for the generation of sequencing libraries demands at least $1 \mathrm{ng}$ genomic DNA; C. parvum oocysts each contain $40 \mathrm{fg}$ DNA [5] thus requiring an estimated $2.5 \times 10^{4}$ highly-purified oocysts. Human stool samples received at diagnostic laboratories tend to be small in volume and contain relatively small numbers of Cryptosporidium oocysts amongst very large numbers of nontarget organisms, mainly bacteria, which is problematic for the production of the purity of genomic DNA required for analysis. Whole genome sequences generated to date have either utilised experimental animal infections for propagation of sufficient material [6] or obtained and processed large volumes of animal faeces from natural infections [7]; both approaches restrict the information available to a small number of sufficiently abundant isolates and may introduce the potential for strain selection bias. The former is most especially unsustainable for large-scale investigations for practical, financial and ethical reasons, particularly for $C$. hominis which has no symptomatic animal model and requires passage in gnotobiotic piglets [8] or immunosuppressed Mongolian gerbils [9]. Enrichment of genomic Cryptosporidium DNA for WGS from stools has recently been described using whole genome amplification but significant contamination was reported [10].

Here we describe the development and validation of a protocol for preparation of genomic Cryptosporidium DNA from routinely submitted diagnostic human stool samples suitable for whole genome sequencing. The method has the following characteristics which specifically address the challenges described above: enhanced purification of oocysts degradation of non-Cryptosporidium contaminants, and use of an NGS library preparation kit capable of processing as little as $1 \mathrm{ng}$ of genomic DNA.

\section{Results and discussion}

\section{Characterisation of isolates prior to WGS}

Characterisation by C. parvum and C. hominis-specific realtime polymerase chain reaction (PCR) revealed no evidence of the presence of more than one species in any of the stools tested. Only the expected species were identified by Sanger sequence analysis of the $18 \mathrm{~S}$ rRNA actin, $h s p 70$ and COWP genes. Gp60 subtypes were identified as shown in Tables 1 and 2. There was no evidence from the sequencing chromatograms that any of the isolates were of mixed populations of Cryptosporidium species or gp60 subtypes.

\section{Evaluation of oocyst preparation methods in the pilot phase}

Salt-floated suspensions of $1 \times 10^{6}$ C. parvum and C. hominis oocysts yielded after IMS, $6.1 \times 10^{5}$ (61\% recovery) and $4.5 \times 10^{5}$ oocysts (45\% recovery, respectively. After bleachtreatment, $3.7 \times 10^{5} \mathrm{C}$. parvum and $2.9 \times 10^{5} \mathrm{C}$. hominis oocysts were counted, sufficient for DNA extraction.

Caesium Chloride $(\mathrm{CsCl})$ density gradient centrifugation of the same original number of oocysts in salt-floated suspension yielded $2 \times 10^{5}$ C. parvum oocysts (20\% recovery) and $<2 \times 10^{4} \mathrm{C}$. hominis oocysts $(<2 \%$ recovery undetectable in counting chamber) and after bleach treatment $1.3 \times 10^{5}$ and $<5.3 \times 10^{3}$ (undetectable), respectively, indicating that IMS was the more efficient method for purification of oocysts derived from small volume stool samples (Table 1). Due to undetectable numbers of oocysts in the $\mathrm{CsCl}$-prepared $\mathrm{C}$. hominis suspension, this was not processed further. Although $\mathrm{CsCl}$ has been used successfully 
Table 1 Properties of Cryptosporidium oocyst and DNA preparations from two pilot phase stool samples

\begin{tabular}{|c|c|c|c|c|c|c|}
\hline \multirow{2}{*}{$\begin{array}{l}\text { Isolate, species } \\
\text { and gp60 } \\
\text { subtype }\end{array}$} & \multirow[t]{2}{*}{ Preparation stage } & \multirow{2}{*}{$\begin{array}{l}\text { qPCR } 185 \\
\text { rRNA gene }\left(C_{T}\right) \\
\text { from original } \\
\text { stool sample }\end{array}$} & \multicolumn{2}{|c|}{$\begin{array}{l}\text { Quantification of Cryptosporidium } \\
\text { processed by IMS }\end{array}$} & \multirow{2}{*}{$\begin{array}{l}\text { Bacterial DNA calculated } \\
\text { from qPCR } 16 \text { s rRNA } \\
\text { gene (ng) (\% reduction } \\
\text { compared with salt-floated } \\
\text { suspension) }\end{array}$} & \multirow[t]{2}{*}{$\begin{array}{l}\text { Total DNA } \\
\text { from Qubit (ng) }\end{array}$} \\
\hline & & & $\begin{array}{l}\text { Numbers of oocysts } \\
\text { counted; genome copies } \\
\text { derived from microscopy } \\
\text { counts }\end{array}$ & $\begin{array}{l}\text { Genome copies } \\
\text { calculated from } \\
\text { qPCR } 18 \text { s rRNA } \\
\text { gene }\end{array}$ & & \\
\hline \multirow[t]{3}{*}{$\begin{array}{l}\text { UKP2, C. parvum } \\
\text { IlaA19G1R2 }\end{array}$} & $\begin{array}{l}\text { Salt-floated } \\
\text { suspension }\end{array}$ & 28.8 & $1.0 \times 10^{6} ; 4.0 \times 10^{6}$ & $4.27 \times 10^{5}$ & 323.1 & ND \\
\hline & $\begin{array}{l}\text { Post IMS, bleach } \\
\text { treated suspension }\end{array}$ & & $3.7 \times 10^{5} ; 1.5 \times 10^{6}$ & $2.99 \times 10^{5}$ & 4.2 (98.7 \% reduction) & 2.44 \\
\hline & $\begin{array}{l}\text { Post } \mathrm{CsCl} \text {, bleach } \\
\text { treated suspension }\end{array}$ & & $1.3 \times 10^{5} ; 5.2 \times 10^{5}$ & $1.99 \times 10^{5}$ & $N D^{a}$ & 1.52 \\
\hline \multirow{2}{*}{$\begin{array}{l}\text { UKH3, C. hominis } \\
\text { IbA10G2 }\end{array}$} & Initial suspension & 26.7 & $1.0 \times 10^{6} ; 4.0 \times 10^{6}$ & $4.6 \times 10^{5}$ & 86.7 & ND \\
\hline & $\begin{array}{l}\text { Post IMS, bleach } \\
\text { treated suspension }\end{array}$ & & $2.9 \times 10^{5} ; 1.2 \times 10^{6}$ & $1.3 \times 10^{6}$ & 4.4 (94.9\% reduction) & 2.68 \\
\hline
\end{tabular}

$N D$, not done

${ }^{a}$ Not tested in order to preserve DNA as total DNA level was low

for oocyst preparation from bulk samples collected repeatedly from a naturally infected animal [7], the collection of bulk or multiple repeat samples is not practical for stool collection from most human patients.

The use of quantitative PCR (qPCR) to derive oocyst numbers in the salt-floated suspensions resulted in estimates 9.4-fold (C. parvum) and 8.6-fold (C. hominis) lower than those derived from microscopic counts of intact oocysts in good condition (Table 1). Either Cryptosporidium DNA was lost during the extraction process or there was uncertainty of the measurements. The presence of PCR inhibitors co-extracted with the DNA would be expected to lead to an underestimation of DNA concentration by qPCR in these stool-derived samples when compared to standard curves derived from cloned template. Oocyst numbers derived from qPCR of DNA extracted from the more highly-purified IMS and $\mathrm{CsCl}$ suspensions were closer to actual microscopic counts than those for the saltfloated suspensions (Table 1); it is likely that DNA from more highly-purified oocysts was more closely represented by the standard curve plasmid DNA and therefore more accurately quantified than that prepared from the salt-floated suspensions.

A substantial decrease in the mass of bacterial DNA was identified after both IMS and bleach-treatment (Table 1) reduced by $94.9 \%$ (C. hominis) and $98.7 \%$ (C. parvum) compared with the salt-floated suspensions. $\mathrm{CsCl}$-prepared C. hominis DNA was not processed for library preparation due to its low total DNA concentration (see below). Total DNA concentration in the DNA extracts from the C. parvum IMS and $\mathrm{CsCl}$-prepared samples and the C. hominis IMS-prepared sample, measured by Qubit fluorometric quantitation, was $>1 \mathrm{ng}$ and therefore sufficient for NGS library preparation.
These measurements highlighted the utility of the IMS and bleaching processes for reduction of extraneous DNA without significantly affecting the amount of Cryptosporidium DNA. Seth-Smith et al. also used IMS to reduce nontarget organisms prior to Chlamydia trachomatis DNA extraction [11] however, in the case of Cryptosporidium, the oocyst wall affords the opportunity to further reduce bacterial contamination with brief sodium hypochlorite treatment without damaging the target DNA, whilst providing challenges with regard to fracturing the oocyst wall prior to DNA extraction when dealing with low numbers of oocysts.

\section{Evaluation of DNA preparation in the main phase}

Of the 17 stools processed nine produced sufficient total DNA for library preparation, of which two contained $C$. hominis and seven $C$. parvum. The median low threshold cycle $\left(C_{T}\right)$ value for suspensions that generated sufficient DNA for whole genome sequencing (27.3, range 23.5-30.9) was significantly lower than for those that did not (30.5, range 28.1-34.0) $(\mathrm{p}=0.009)$. Although there was some overlap in $C_{T}$ values, suspensions containing oocysts that were in good condition were more likely to produce whole genome sequences (Table 2). Although qPCR was not a reliable indicator of oocyst abundance in salt floated suspensions in the pilot phase, the combination of $\mathrm{qPCR}$, oocyst counts and visual condition proved to be a good and practical predictor of suitability of salt-floated suspensions for further processing in the main phase (Table 2 Fig. 1). The importance of microscopic examination is notable because although oocyst counts are time consuming so is IMS processing (which is also expensive), and pre-screening in this way would maximise use of resources in larger scale applications. Post IMS there was clear delineation of $C_{T}$ values between sufficient and insufficient preparations the 
Table 2 Assessment of Cryptosporidium preparation from 17 stool samples containing C. hominis or C. parvum oocysts

\begin{tabular}{|c|c|c|c|c|c|c|c|c|}
\hline \multirow[b]{2}{*}{ Sample } & \multirow[b]{2}{*}{ Species and gp60 subtype } & \multicolumn{3}{|c|}{ Initial suspension prior to processing by IMS } & \multicolumn{4}{|c|}{ DNA extracted from IMS purified oocysts } \\
\hline & & qPCR 185 rRNA $C_{T}$ & $\begin{array}{l}\text { Number of } \\
\text { oocysts counted }\end{array}$ & Visual condition of oocysts & qPCR 185 rRNA $C_{T}$ & $\begin{array}{l}\text { Calculated } \\
\text { genome copies }\end{array}$ & $\begin{array}{l}\text { Mass of } \\
\text { DNA (ng) }\end{array}$ & $\begin{array}{l}>1 \mathrm{ng} \text { DNA available } \\
\text { for library preparation } \\
\text { (isolate reference number) }\end{array}$ \\
\hline 1 & C. hominis laA14R3 & ND & $1.9 \times 10^{7}$ & Good & 17.7 & $5.53 \times 10^{7}$ & 77 & Yes (UKH4) \\
\hline \multirow[t]{2}{*}{2} & \multirow[t]{2}{*}{ C. hominis IbA10G2 } & \multirow[t]{2}{*}{23.5} & \multirow[t]{2}{*}{$1.6 \times 10^{7}$} & \multirow[t]{2}{*}{ Good } & \multirow[t]{2}{*}{20.0} & \multirow[t]{2}{*}{$1.24 \times 10^{7}$} & \multirow[t]{2}{*}{49.55} & Yes \\
\hline & & & & & & & & (UKH5) \\
\hline 3 & C. hominis IdA18 & 29.3 & $2.1 \times 10^{5}$ & Good & 25.7 & $1.64 \times 10^{5}$ & $\begin{array}{l}\text { Below } \\
\text { threshold }\end{array}$ & No \\
\hline 4 & C. parvum IlaA15G1R1 & 31.6 & $7.5 \times 10^{4}$ & Good & 25.9 & $1.49 \times 10^{5}$ & 0.00 & No \\
\hline 5 & C. parvum IlaA15G1R2 & 31.1 & $5.0 \times 10^{4}$ & Good & 25.1 & $2.36 \times 10^{5}$ & 0.00 & No \\
\hline 6 & C. parvum IlaA15G2R1 & 28.1 & $3.6 \times 10^{5}$ & $\begin{array}{l}\text { OK - a few empty oocysts, } \\
\text { didn't stain well }\end{array}$ & 28.6 & $2.66 \times 10^{4}$ & 0.00 & No \\
\hline \multirow[t]{2}{*}{7} & \multirow[t]{2}{*}{ C. parvum IlaA18G2R1 } & \multirow[t]{2}{*}{29.1} & \multirow[t]{2}{*}{$1.5 \times 10^{6}$} & \multirow[t]{2}{*}{ Good } & \multirow[t]{2}{*}{22.2} & \multirow[t]{2}{*}{$2.99 \times 10^{6}$} & \multirow[t]{2}{*}{5.45} & Yes \\
\hline & & & & & & & & (UKP3) \\
\hline \multirow[t]{2}{*}{8} & \multirow[t]{2}{*}{ C. parvum IlaA15G2R1 } & \multirow[t]{2}{*}{25.5} & \multirow[t]{2}{*}{$2.8 \times 10^{6}$} & \multirow[t]{2}{*}{ Good } & \multirow[t]{2}{*}{20.1} & \multirow[t]{2}{*}{$5.99 \times 10^{6}$} & \multirow[t]{2}{*}{18.65} & Yes \\
\hline & & & & & & & & (UKP4) \\
\hline \multirow[t]{2}{*}{9} & \multirow[t]{2}{*}{ C. parvum IlaA15G2R1 } & \multirow[t]{2}{*}{27.5} & \multirow[t]{2}{*}{$9.1 \times 10^{5}$} & Good & 23.2 & $1.52 \times 10^{6}$ & 2.68 & Yes \\
\hline & & & & & & & & (UKP5) \\
\hline 10 & C. parvum IlaA15G2R1 & 27.1 & $2.7 \times 10^{6}$ & Good & 23.4 & $1.32 \times 10^{6}$ & 4.40 & Yes \\
\hline & & & & & & & & (UKP6) \\
\hline 11 & C. parvum IlaA17G1R1 & 23.8 & $9.0 \times 10^{6}$ & Good & 20.3 & $1.01 \times 10^{7}$ & 28.65 & Yes \\
\hline & & & & & & & & (UKP7) \\
\hline 12 & C. parvum IlaA19G2R1 & 30.4 & $1.1 \times 10^{6}$ & Good & 24.4 & $3.74 \times 10^{5}$ & 0.8 & No \\
\hline 13 & C. parvum IlaA19G2R1 & 29.2 & $1.1 \times 10^{6}$ & Good & 28.7 & $2.53 \times 10^{4}$ & 0.00 & No \\
\hline 14 & C. parvum IlaA19G2R1 & 30.6 & $5.2 \times 10^{5}$ & OK & 31.8 & $3.58 \times 10^{3}$ & 0.00 & No \\
\hline 15 & C. parvum IlaA19G2R1 & 34.0 & $3.9 \times 10^{4}$ & OK - a few empty oocysts & $\begin{array}{l}\text { No amplicon } \\
\text { detected }\end{array}$ & 0 & ND & No \\
\hline 16 & C. parvum IIdA22G1 & 28.4 & $2.3 \times 10^{6}$ & Good & 21.9 & $3.62 \times 10^{6}$ & 6.55 & Yes \\
\hline & & & & & & & & (UKP8) \\
\hline 17 & C. parvum IIdA24G1 & 30.9 & $1.2 \times 10^{6}$ & Good & 23.9 & $1.01 \times 10^{6}$ & 2.88 & Yes $^{a}$ \\
\hline
\end{tabular}




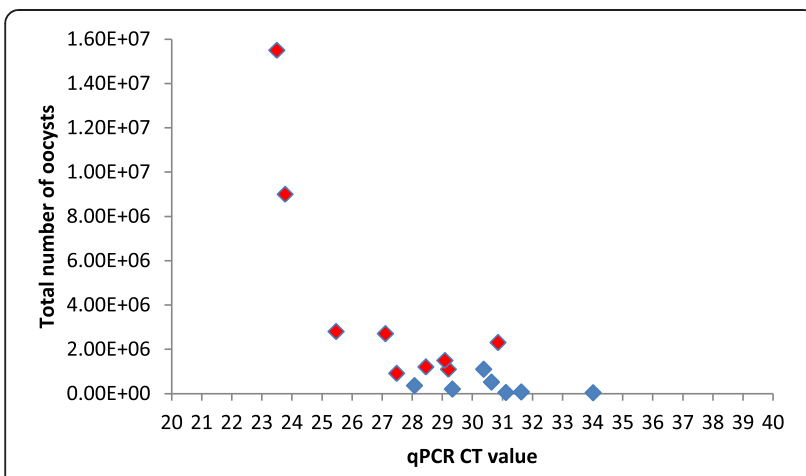

Fig. 1 Relationship between total oocyst numbers, $C_{T}$ values and concentration of recovered DNA. Oocyst numbers (counted by microscopy), and $C_{T}$ values in the salt-floated suspension were determined prior to processing, and compared to final DNA recovery. Red, WGS successful; Blue, <1 ng DNA available (below manufacturer's threshold for library preparation)

median $\mathrm{C}_{\mathrm{T}}$ value for those that generated sufficient DNA for whole genome sequencing (21.9 range 17.7-23.9) was significantly lower than those that did not (25.9, range 24.4-31.8) $(\mathrm{p}=0.0009)$. There was a significant relationship between Cryptosporidium 18S rRNA gene qPCR and mass of DNA in the final extracts $\left(R^{2}=8.315\right.$, see Fig. 2$)$ indicating this comprised a sufficiently large proportion of Cryptosporidium DNA. Although $16 \mathrm{~S}$ rRNA gene qPCR had proved useful in the pilot phase to demonstrate reduction in bacterial DNA, it was not used in the main phase. Cryptosporidium 18S rRNA gene qPCR was evidently more useful in process monitoring, with the pilot phase results showing that Cryptosporidium genome copies could more accurately be derived from these data, with the additional benefit of reduced analysis preserving material for downstream use.

\section{Results of next generation sequencing}

Including both pilot and main phases a total of three $C$. hominis and seven $C$. parvum whole genomes were successfully sequenced, reads aligned to reference genomes,

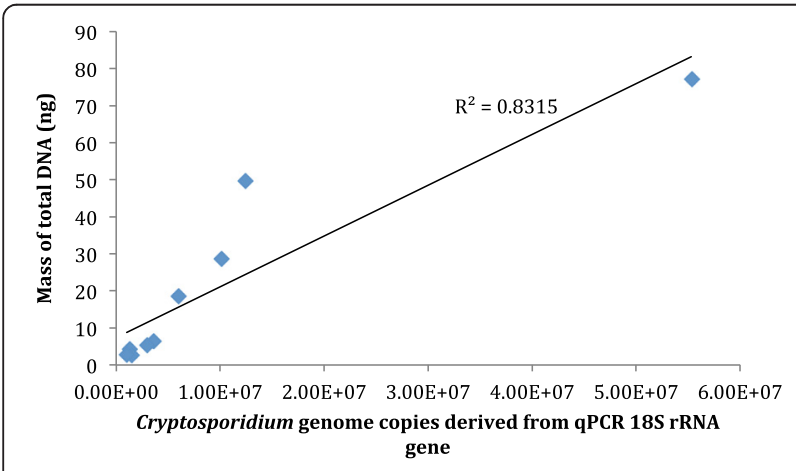

Fig. 2 Relationship between Cryptosporidium genome copies and total DNA in extracts prior to whole genome sequencing and contigs de novo assembled and annotated, with an additional sequence generated via the $\mathrm{CsCl}$ method for the C. parvum isolate in the pilot phase.

In the pilot phase sequencing C. parvum UKP2 using the Illumina MiSeq achieved $100 \%$ coverage of the C. parvum IOWA II reference genome at a mean 51.80X depth using the IMS-based method, $100 \%$ coverage at a mean 46.84X depth using the CsCl-based method, and for C. hominis UKH3 $98 \%$ coverage of the $C$. hominis TU502 reference genome at a mean $34.71 \mathrm{X}$ depth (Table 3). When aligned to the reference genomes, $90.30 \%$ of reads from C. hominis UKH3, $92.51 \%$ of reads from C. parvum UKP2 IMS preparation and $81.86 \%$ reads from C. parvum $\mathrm{UKP} 2 \mathrm{CsCl}$ preparation mapped to the reference sequences the percentage of unmapped reads were likely from residual bacterial contamination (although this appears to be low) and sequencing errors and was greater for the $\mathrm{CsCl}$ preparation compared to the IMS preparations.

In the main phase eight of the nine DNA extracts generated high-quality data using the Illumina HiSeq the proportion of reads mapping to the reference sequence ranged from $80.90 \%$ to $89.06 \%$ with 0.96 to 0.99 fraction of the reference genome covered confirming the suitability of the Illumina Nextera XT sample preparation for generation of Cryptosporidium genomes from clinical isolates (Table 3). One sample failed to produce sufficient data probably because insufficient library DNA was added at the pooling stage.

The post-assembly genome improvement protocol (PAGIT) [12] improved assemblies produced from the sequenced reads were of high-quality and statistics describing them are given in Table 4. Of the 10 assemblies 8 could be assembled into less than 70 scaffolds, with the assembly N50 metric equal to just over $1 \mathrm{Mb}$ for most assemblies (i.e. $50 \%$ of the genome has been assembled into scaffolds with a minimum length of $1 \mathrm{Mb}$ ). Using the Bowtie2 read aligner [13] with the default settings we were able to align between $82.0 \%$ and $96.2 \%$ of sequenced reads as concordant pairs to the final genome assemblies, indicating that the genome assemblies are relatively complete. Rapid annotation transfer tool (RATT) [14] was able to transfer between $92.1 \%$ and $95.9 \%$ of the 3,805 gene annotations from C. parvum Iowa II to the assemblies thus providing a sound basis for further studies into sequence and structural variation. Although notably greater depth of coverage was achieved with the Illumina HiSeq (26.9-209.2 X) than with the MiSeq, the MiSeq genome assemblies were nonetheless of equivalent quality: see the statistics for UKH3 and UKP2 in Table 4.

In order to investigate the possibility of bacterial contamination for each isolate, any read pairs that did not map concordantly to the final de novo contig assemblies were assembled separately. From these assemblies of contaminants, contigs greater than 300 bp were blasted 
Table 3 Quality of whole genome sequences generated directly from stools containing C. hominis and C. parvum

\begin{tabular}{|c|c|c|c|c|c|c|}
\hline $\begin{array}{l}\text { Isolate; species and } \\
\text { gp60 subtype; } \\
\text { BioProject number }\end{array}$ & $\begin{array}{l}\text { Total \# base } \\
\text { pairs sequenced } \\
\text { (after merging reads) }\end{array}$ & $\begin{array}{l}\text { Total \# base } \\
\text { pairs mapped to } \\
\text { reference sequence }\end{array}$ & $\begin{array}{l}\text { Proportion of } \\
\text { Cryptosporidium } \\
\text { DNA compared } \\
\text { to background }\end{array}$ & $\begin{array}{l}\% \text { of reference } \\
\text { genome covered }\end{array}$ & $\begin{array}{l}\text { Mean depth } \\
\text { on reference } \\
\text { sequence }\end{array}$ & $\begin{array}{l}\% \text { AT content } \\
\text { of reads mapped } \\
\text { to reference } \\
\text { sequence }\end{array}$ \\
\hline \multicolumn{7}{|l|}{ Pilot phase } \\
\hline $\begin{array}{l}\text { UKH3 } \\
\text { (IMS preparation) }\end{array}$ & $337,791,948$ & $305,024,423^{\mathrm{a}}$ & $90.30 \%$ & $98 \%$ & $34.71 \times$ & $67.49 \%$ \\
\hline \multicolumn{7}{|l|}{ C. hominis IbA10G2 } \\
\hline \multicolumn{7}{|l|}{ PRJNA253834 } \\
\hline $\begin{array}{l}\text { UKP2 } \\
\text { (IMS preparation) }\end{array}$ & $510,081,295$ & $471,881,392^{b}$ & $92.51 \%$ & $100 \%$ & $51.80 \times$ & $67.92 \%$ \\
\hline \multicolumn{7}{|l|}{ C. parvum IlaA19G1R2 } \\
\hline \multicolumn{7}{|l|}{ PRJNA253836 } \\
\hline UKP2 (CsCl preparation) & $521,277,984$ & $426,692,177^{b}$ & $81.86 \%$ & $100 \%$ & $46.84 \times$ & $67.85 \%$ \\
\hline \multicolumn{7}{|l|}{ C. parvum IlaA19G1R2 } \\
\hline \multicolumn{7}{|l|}{ PRJNA253836 } \\
\hline \multicolumn{7}{|l|}{ Main phase } \\
\hline UKH4 & $2,164,426,378$ & $1,828,866,488^{a}$ & $84.50 \%$ & $96 \%$ & $209.17 \times$ & $62.72 \%$ \\
\hline \multicolumn{7}{|l|}{ C. hominis laA14R3 } \\
\hline \multicolumn{7}{|l|}{ PRJNA253838 } \\
\hline UKH5 & $2,182,317,271$ & $1,765,458,438^{a}$ & $80.90 \%$ & $96 \%$ & $201.92 \times$ & $63.03 \%$ \\
\hline \multicolumn{7}{|l|}{ C. hominis IbA10G2 } \\
\hline \multicolumn{7}{|l|}{ PRJNA253839 } \\
\hline UKP3 & $1,703,132,267$ & $1,514,828,932^{b}$ & $88.94 \%$ & $99 \%$ & $166.42 \times$ & $63.55 \%$ \\
\hline \multicolumn{7}{|l|}{ C. parvum IlaA18G2R1 } \\
\hline \multicolumn{7}{|l|}{ PRJNA253840 } \\
\hline UKP4 & $1,967,147,533$ & $1,751,979,030^{b}$ & $89.06 \%$ & $99 \%$ & $192.48 \times$ & $63.60 \%$ \\
\hline \multicolumn{7}{|l|}{ C. parvum IlaA15G2R1 } \\
\hline \multicolumn{7}{|l|}{ PRJNA253843 } \\
\hline UKP5 & $288,922,509$ & $244,528,063^{b}$ & $84.63 \%$ & $99 \%$ & $26.86 \times$ & $67.67 \%$ \\
\hline \multicolumn{7}{|l|}{ C. parvum IlaA15G2R1 } \\
\hline \multicolumn{7}{|l|}{ PRJNA253845 } \\
\hline UKP6 & $1,169,379,989$ & $954,176,437^{b}$ & $81.60 \%$ & $99 \%$ & $104.83 \times$ & $67.73 \%$ \\
\hline \multicolumn{7}{|l|}{ C. parvum IlaA15G2R1 } \\
\hline \multicolumn{7}{|l|}{ PRJNA253846 } \\
\hline UKP7 & $795,715,168$ & $708,613,859^{b}$ & $89.05 \%$ & $99 \%$ & $77.85 \times$ & $63.64 \%$ \\
\hline \multicolumn{7}{|l|}{ C. parvum IlaA17G1R1 } \\
\hline \multicolumn{7}{|l|}{ PRJNA253847 } \\
\hline UKP8 & $1,896,616,473$ & $1,587,380,412^{b}$ & $83.70 \%$ & $98 \%$ & $174.39 \times$ & $63.20 \%$ \\
\hline \multicolumn{7}{|l|}{ C. parvum $\| \mathrm{dA} 22 \mathrm{G} 1$} \\
\hline PRJNA253848 & & & & & & \\
\hline
\end{tabular}

${ }^{a}$ mapped against $C$. hominis TU502 v1 reference sequence (Bioproject PRJNA15585)

${ }^{b}$ mapped against the C. parvum IOWA II v1 reference sequence (Bioproject PRJNA15586) using default mapping conditions

[15] against all Cryptosporidium assemblies available on the National Center for Biotechnology Information (NCBI: C. muris RN66, C. parvum Iowa II, Cryptosporidium sp. chipmunk LX-2015, and C. hominis TU502) [16]. Using a Basic Local Alignment Search Tool (BLAST) e-value $<1^{-10}$ potential Cryptosporidium sequences were filtered out of these assemblies. The remaining non-Cryptosporidium contigs (column "NC" in Table 4) were subsequently blasted against all bacterial genomes available on the $\mathrm{NCBI}$, and using an e-value $<1^{-10}$ the total amount of 
Table 4 Summary of improvements made to the initial genome assemblies by PAGIT

\begin{tabular}{|c|c|c|c|c|c|c|c|}
\hline Isolate & $\begin{array}{l}\text { Initial assembly } \\
\text { statistics: No. } \\
\text { N50 Av. (kb) }\end{array}$ & $\begin{array}{l}\text { Gaps closed } \\
\text { by IMAGE }\end{array}$ & $\begin{array}{l}\text { ICORN Sequence } \\
\text { corrections: } \\
\text { SNP Indel }\end{array}$ & $\begin{array}{l}\text { RATT Gene } \\
\text { annotations transferred }\end{array}$ & $\begin{array}{l}\text { Final assembly } \\
\text { statistics: No. } \\
\text { N50 Av. Size (kb) }\end{array}$ & $\begin{array}{l}\text { Paired reads } \\
\text { aligning } \\
\text { concordantly (\%) }\end{array}$ & $\begin{array}{l}\text { Contaminant } \\
\text { sequence NC } \\
\mathrm{BCT}(\mathrm{kb})\end{array}$ \\
\hline UKH3 & 190294.74 .9 & 330 & 21027 & 3649 & 341000268.79136 & 87.5 & 41.10 .0 \\
\hline UKH4 & 237529.14 .0 & 343 & 58499 & 3503 & 110103284.49293 & 93.5 & 40.114 .1 \\
\hline UKH5 & 130529.97 .0 & 437 & 18961 & 3569 & 651006142.49257 & 96.2 & 6.92 .4 \\
\hline UKP2 & 3084105.23 .1 & 174 & 18248 & 3600 & 671011136.79164 & 85.1 & 89.61 .6 \\
\hline UKP3 & 91957.510 .0 & 259 & 22660 & 3546 & 551009167.79224 & 90.2 & 2.00 .0 \\
\hline UKP4 & 196649.34 .8 & 334 & 170108 & 3553 & 52891177.49222 & 91.0 & 7.30 .7 \\
\hline UKP5 & 38309.72 .4 & 1435 & 34180 & 3527 & 471031198.49329 & 88.6 & 31.414 .6 \\
\hline UKP6 & 1689540.30 .8 & 274 & 3144394 & 3565 & 417101422.79471 & 81.2 & 685.769 .5 \\
\hline UKP7 & 115830.27 .8 & 321 & 18580 & 3556 & 551026168.79278 & 90.4 & 2.50 .0 \\
\hline UKP8 & 179242.05 .2 & 356 & 15247 & 3545 & 631015147.49290 & 93.5 & 37.924 .4 \\
\hline
\end{tabular}

The assembly statistics (initial and final) include the number of scaffolds, scaffold N50 metric, scaffold mean length (Av.), and the total size of the final assembly. Gene annotations were transferred by RATT out of a total of 3805 gene annotations in the reference assembly. The "Contaminant sequence" column refers to the total length non-concordantly mapping read pairs that have been assembled separately and identified as non-cryptosporidium sequence (NC) and bacterial sequence $(B C T)$

bacterial sequence was identified (column "BCT" in Table 4). The amount of contaminating sequence was too small, too fragmented (the longest contig from any of these assemblies was $971 \mathrm{bp}$ ), or too low in complexity to reliably identify any particular contaminating bacteria species.

The serine tri-nucleotide repeat rich gp60 gene sequence is used in sub-typing to study the taxonomy and transmission of the Cryptosporidium parasite [17, 18]. Searching for the gp60 gene sequences from each isolate in the respective assemblies with BLASTN produced $100 \%$ alignments with an E-value $=0.0$ of 681 to 755 bp in length: although no alignments were reported over the low complexity regions at the start of the gp60 gene because BLAST filters out such regions before aligning sequences. The $18 \mathrm{~S}$ rRNA gene sequences were similarly found by BLAST in the assemblies with $100 \%$ sequence identity, split into two alignments due a low complexity region in the middle of the sequence with each alignment having a length of around $250 \mathrm{bp}$ to $400 \mathrm{bp}$. Exceptions were UKH4, where two copies (i.e. four alignments of $250 \mathrm{bp}$ to $400 \mathrm{bp}$ ) of the $18 \mathrm{~S}$ rRNA gene region could be found, all between $99.2 \%$ to $100.0 \%$ sequence identity, and UKH5 where there were three BLAST hits of $100.0 \%$ sequence identity (also with $250 \mathrm{bp}$ to $400 \mathrm{bp}$ lengths). No evidence was found of mixed species populations. Note that five copies of the 18S rRNA gene are found in the C. parvum Iowa II reference genome assembly and this indicates that the assembly process used in this study has collapsed the $18 \mathrm{~S}$ rRNA gene regions, typically into just one copy.

The genome data from this study have been deposited on the NCBI (http://www.ncbi.nlm.nih.gov/) database as individual BioProjects (Table 3) under the umbrella BioProject PRJNA215218.

\section{Conclusions}

We have developed a method for the high-quality sequencing of Cryptosporidium spp. isolates using the transposome-based Nextera XT library preparation and Illumina sequencing platform directly from routinely submitted human stools left over from diagnostic testing. This has the advantage of reducing the requirement for the use of animals for in vivo amplification of oocysts to extract sufficient genomic Cryptosporidium DNA for whole genome sequencing as was used to generate the reference genomes $[3,4]$ and potentially extending the possibilities for more widespread investigation of Cryptosporidium. The generation and comparison of benchmark genomes from all Cryptosporidium species and genotypes would help establish more definitive taxonomy than is currently possible based on the analysis of only a tiny proportion of the genome using Sanger sequencing even of multiple loci [19]. Global surveillance and analysis of Cryptosporidium genomes from widespread and representative infections would be valuable for identification of possible drug targets, new diagnostic, virulence and subtyping markers.

The samples prepared in this study were chosen because of sufficient sample volume (1 to $2 \mathrm{ml}$ ) and adequate concentration of oocysts in the salt-floated suspension. Even so the concentration of DNA available after the purification processes was often at the limit of that acceptable for the Illumina technology used. It is evident that to extend the utility of Illumina sequencing to stools of smaller volumes or with lower concentrations of oocysts, strategies such as the application of kits requiring $<1$ ng DNA would be useful, as might whole genome amplification (WGA) which has proven capable of increasing genomic DNA in Cryptosporidium samples [20] and may be of use for producing sufficient material $[10,11]$. 
We are currently using this technique to compare Illumina sequencing libraries generated from native and WGA-amplified DNA from clinical samples [Pachebat personal communication]. This allows the approaches to be compared and investigated for artifactual mutations that, for example, have been reported to occur at a rate of approximately 1 in $10^{5}$ to $10^{6}$ for $\varphi 29$-based methods [21]. Although it required additional steps and is susceptible to contamination, WGA could expand the application of Illumina sequencing to still more samples [10].

We conclude that in our laboratory using the current Nextera XT library preparation methods the following selection criteria are valuable predictors of likely successful generation of high-quality C. parvum or C. hominis genome sequences from stool samples:

- Original stool sample volume $>1 \mathrm{ml}$

- Initial salt-floated oocyst suspension $18 \mathrm{~S}$ rRNA gene qPCR $C_{\mathrm{T}}<30.9$ AND $>9 \times 10^{5}$ oocysts that are in good condition with very few empty oocysts

- Post-IMS-bleach treatment $18 \mathrm{~S}$ rRNA gene qPCR $\mathrm{C}_{\mathrm{T}}<24.0$ and Qubit result $>1$ ng total DNA

However in other laboratories different factors (such as PCR efficiency) may affect measurements, and the use of different criteria may be necessary.

We have described the generation of high-quality sequences of Cryptosporidium directly from stool samples and assembled these into 10 high-quality draft genomes. Our method coupled with the availability of reference sequences for comparison, removes the requirement for the use of animals to passage and amplify oocyts prior to genome sequencing. It reduces the cost, and extends the potential for this technology to be applied to the rapid and accurate genomic characterisation of clinical isolates, for the purposes of control of transmission, and treatment during outbreaks.

\section{Methods}

Source and characterisation of Cryptosporidium oocysts

The work was undertaken in two phases: a pilot phase in which two stools were processed, and a main phase in which a further 17 stools were processed.

In the pilot phase of the project, two Cryptosporidiumpositive stool samples submitted for diagnosis of diarrhoea and subsequent identification of Cryptosporidium spp. were selected using the criteria of volume $\geq 1 \mathrm{ml}$ and adequate oocyst numbers indicated by low threshold cycle $\left(\mathrm{C}_{\mathrm{T}}\right)$ in an 18S rRNA gene real-time PCR assay [22] (Table 1). Cryptosporidium species were identified by Sanger sequence analysis of the $\sim 300 \mathrm{bp}$ fragment of the $18 \mathrm{~S}$ rRNA gene and each sample confirmed as containing either C. parvum or C. hominis only using a species-specific multiplex genotyping real-time PCR targeting the $C$. parvum Lib13 and $C$. hominis A135 loci [22, 23] Cryptosporidium Reference Unit unpublished). Gp60 subtypes were identified by sequencing $\sim 850$ bp of the gp60 gene [18]. Additional Sanger sequence data was obtained for the actin, $h s p 70$ and Cryptosporidium oocyst wall protein $(C O W P)$ genes as described previously [24].

In the main phase of the project, 17 further samples meeting the stool selection criteria above, and having a range of gp60 subtypes, were selected for purification and processing; three containing $C$. hominis and $14 C$. parvum (Table 2).

Ethics statement: The protozoal isolates were collected as part of routine clinical service provision [25]. The study of de-identified, purified protozoal DNA and not human subjects meant that formal Human Ethics Committee approval or Informed Patient Consent was not required.

\section{Purification of Cryptosporidium oocysts}

Cryptosporidium oocysts were harvested from 1 to $2 \mathrm{ml}$ of each faecal sample using saturated salt-flotation to generate a partially purified suspension as described previously [25]. The number of oocysts in these suspensions was estimated by staining with equal volume of FITC-labelled anti-Cryptosporidium monoclonal antibody (Crypto-Cel, Cellabs, Australia) and counting using a Neubauer improved haemocytometer (C-Chip, Peqlab, Sarisbury Green, UK).

Oocysts were further purified from suspension by immunomagnetic separation (IMS). In the pilot phase, a total of $1 \times 10^{6}$ salt-floated oocysts were made up to $10 \mathrm{ml}$ with reverse osmosis (RO) water and processed through the Isolate ${ }^{\curvearrowleft}$ IMS kit (TCS Biosciences, Botolph Claydon, UK) according to the manufacturer's instructions. Oocysts were dissociated from the magnetic beads into $1.5 \mathrm{ml}$ microfuge tubes (Elkay, Basingstoke, UK), and the volume adjusted to $1 \mathrm{ml}$ with $\mathrm{RO}$ water prior to surface sterilisation. In the main phase salt-floated oocysts were treated similarly, but all available oocysts were used (ranging from $3.9 \times 10^{4}$ to $1.9 \times 10^{7}$, see Table 2) and dissociated oocysts adjusted to $200 \mu \mathrm{L}$ with $\mathrm{RO}$ water prior to surface sterilisation.

To investigate an alternative to IMS in the pilot phase, $1 \times 10^{6}$ oocysts were also purified from the salt-floated suspensions by caesium chloride $(\mathrm{CsCl})$ gradient centrifugation as described by Upton [26], the final pellets resuspended to $1 \mathrm{ml}$ in $\mathrm{RO}$ water and oocysts enumerated by microscopy as described above prior to surface sterilisation.

\section{Surface sterilisation of Cryptosporidium oocysts}

To degrade residual contaminants, each purified oocyst suspension was treated briefly with an equal volume of $0.6 \%$ active chlorine as sodium hypochlorite (VWR, Lutterworth, UK) and washed three times with nucleasefree water by centrifugation at $1,100 \mathrm{X} g$ for $5 \mathrm{~min}$ using a swing rotor and soft acceleration-deceleration profile 
to minimise damage to oocysts. The pellets were finally resuspended in $215 \mu \mathrm{L}$ of nuclease-free water, $15 \mu \mathrm{L}$ used for oocyst enumeration as described above and $200 \mu \mathrm{L}$ for DNA extraction.

\section{DNA preparation and characterisation}

Genomic DNA was prepared from $200 \mu \mathrm{L}$ final Cryptosporidium oocyst suspensions by first performing eight cycles of freezing in liquid nitrogen for $1 \mathrm{~min}$ and thawing at $95{ }^{\circ} \mathrm{C}$ for 1 min, and then using the QIAamp DNA extraction kit (Qiagen, Manchester, UK) according to the manufacturer's instructions and finally eluting in $50 \mu \mathrm{L}$ nuclease-free water. Maximum recovery tips (Axygen Inc, USA) and DNA LoBind tubes (Eppendorf AG, Germany) were used in all subsequent DNA quantification and sequencing library preparation steps.

To investigate the efficacy of Cryptosporidium purification in the pilot phase, bacterial, Cryptosporidium and total DNA concentrations were measured as described below in $50 \mu \mathrm{L}$ samples taken from intermediate stages of the oocyst purification process and extracted as described above, as well as in the final DNA extracts. To assess suitability for NGS library preparation in the main phase of the study, all final extracts were assayed for total DNA concentrations and specific quantification of Cryptosporidium DNA as described below.

Estimation of bacterial load was performed by realtime quantitative (q)PCR of the 16S rRNA gene using neat genomic DNA against standards created as described by Jones et al. [27], except that a pure culture of Escherichia coli was used as template material. Serial dilutions of $10^{0}, 10^{-2}, 10^{-4}, 10^{-6}, 10^{-8}$ and $10^{-10}$ were used in subsequent qPCR reactions using a C100 thermal cycler (BioRad, Hercules, USA) and CFX96 optical detector (BioRad). Reactions were completed in $20 \mu \mathrm{L}$ volumes consisting of $10 \mu \mathrm{L}$ of SsoAdvanced SYBR Green Supermix (BioRad) at a final concentration of $1 \mathrm{x}, 400 \mathrm{nM}$ of each of the forward and reverse primers, as described by Kim et al. [28], and $3 \mu \mathrm{L}$ of genomic DNA. The final volume was made up with PCR grade water (Roche Diagnostics Limited, West Sussex, UK).

Total DNA concentration in genomic DNA extracts was measured using the Qubit dsDNA HS Assay Kit with the Qubit 1.0 fluorometer (Invitrogen, Paisley, UK) according to the manufacturer's instructions. A mass of $>1$ ng DNA per extract was required for the Nextera XT library preparation (Illumina, Little Chesterford, UK). DNA samples below $0.2 \mathrm{ng} \mu \mathrm{L}^{-1}$ were concentrated by evaporation (SpeedVac, Thermo Scientific, Loughborough, UK), then resuspended in ultrapure water (Illumina) to $0.2 \mathrm{ng} \mu \mathrm{L}^{-1}$ for subsequent library preparation.

Specific quantification of Cryptosporidium DNA was performed by qPCR of the $18 \mathrm{~S}$ rRNA gene using a protocol modified from Hadfield et al., [22]; only primers CRU18SF and CRU18SR (Integrated DNA Technologies, Glasgow, UK) at $900 \mathrm{nM}$, and the carboxyfluorescein-labelled minor groove binding TaqMan probe CRU18STM (Applied Biosystems, Warrington, UK) at $100 \mathrm{nM}$, were included. DNA concentration was estimated by comparing sample $\mathrm{C}_{\mathrm{T}}$ with a standard curve created by testing linearised plasmid clones of the C. hominis $18 \mathrm{~S}$ rRNA target region [22] serially diluted ten-fold in nuclease-free water, providing $10^{1}$ to $10^{7}$ copies per reaction. Each oocyst DNA extract was tested in triplicate and mean concentration calculated. $C_{T}$ values were recorded and converted to oocyst equivalents $\mathrm{mL}^{-1}$ based on published evidence that each oocyst contains 20 copies of the 18S rRNA gene [29].

$\mathrm{C}_{\mathrm{T}}$ values from initial suspensions and fully purified DNA were compared using a Mann-Whitney $U$ test (Epi-info version 6, Centers for Disease Control and Prevention, USA). The reliability of the linear relationship between genome copies and mass of DNA in the final purified DNA extracts was measured by calculating the correlation coefficient (MS Excel).

\section{Next Generation Sequencing and Analysis}

Barcoded paired-end libraries were created for each isolate with $1 \mathrm{ng}$ of DNA using the Nextera XT DNA sample preparation kit (Version C protocol, Illumina). Amplicons $>500$ bp were size selected in the post-PCR purification steps. The resulting Nextera XT libraries were very low concentration, so after quantification by Qubit HS DNA assay, were pooled to give a $0.1 \mathrm{nM}$ concentration and concentrated using a SpeedVac. In the initial phase, the Nextera XT libraries were sequenced on a MiSeq (Illumina) using $2 \times 151$ bp reads. In the main phase, libraries were sequenced on a HiSeq 2500 (Illumina) using a $2 \times 151 \mathrm{bp}$ rapid run.

Bioinformatics analysis was performed using CLC Genomics Workbench version 7.04 (CLC Bio, Aarhus, Denmark). Briefly, reads were paired, overlapping reads within a read pair merged, and trimmed based on a quality limit of 0.05 , with a maximum of 2 , ambiguities. To check sequencing coverage and depth, reads were subsequently mapped to the appropriate contemporaneous reference genomes, C. hominis TU502 v1 (Bioproject PRJNA 15585) and C. parvum Iowa II v1 (Bioproject PRJNA 15586) using CLC Genomics Workbench default settings (Masking mode $=$ no masking, Mismatch cost $=2$, Insertion cost $=3$, Deletion cost $=3$, Length fraction $=0.5$, Similarity fraction $=0.8$, Global alignment $=$ No, Auto-detect paired distances $=$ Yes, Non-specific match handling $=$ Map randomly). Reads were also mapped to the $C$. hominis and C. parvum reference genomes using the Bowtie2 read aligner [13], with default settings, to the following quality parameters: high sequence identity and similar GC content ( $\sim 30 \%)$ to the reference genomes, 
a high-proportion of target DNA compared to background, and at least $30 \mathrm{X}$ average sequencing depth.

De novo contig assembly for each isolate was performed using CLC Genomics Workbench (Mapping Mode $=$ Create simple contig sequences, Automatic bubble size $=$ Yes, Minimum contig length $=200 \mathrm{bp}$, Automatic word size $=$ Yes, Perform scaffolding $=$ Yes, Autodetect paired distances $=$ Yes, Min distance $=180 \mathrm{bp}$, Max distance $=$ $500 \mathrm{bp}$ ). The CLC de novo contig assemblies were improved using the post-assembly genome improvement protocol, PAGIT [12]. In brief, scaffolds were ordered using algorithm based automatic contiguation of assembled sequences (ABACAS) [30] against the C. parvum Iowa II reference genome; this genome comprises 18 contigs and mapping the assemblies to it generated 18 pseudomolecules that contained most of the assembled sequences, with typically 100 to 200 further much smaller scaffolds that could not be associated with the reference genome. Next, iterative mapping and assembly for gap elimination (IMAGE) [31] was used to close sequencing gaps in scaffolds of at least $500 \mathrm{bp}$. Smaller scaffolds were removed at this stage. Iterative Correction of Reference Nucleotide (ICORN) [32] was then used to correct single-base errors and small insertions and deletions of up to $3 \mathrm{bp}$. Lastly, the C. parvum Iowa II annotation was transferred onto the 18 pseudomolecules using rapid annotation transfer tool (RATT) [14]. The improvements made to the CLC assemblies using the PAGIT protocol were documented and are summarised in Table 4.

\section{Availability of supporting data}

Whole genome sequencing data is deposited on the National Centre for Biotechnology Information (http:// www.ncbi.nlm.nih.gov/) GenBank database as individual BioProjects (PRJNA253834, PRJNA253836, PRJNA253838PRJNA253840, PRJNA253843, PRJNA253845-PRJNA2538 48) under the umbrella Bioproject PRJNA215218. 18S rRNA, gp60, hsp70, COWP and actin gene Sanger sequences are deposited under accession numbers KM085018KM085027, KM012040-KM012055 and KP280061."

\footnotetext{
Abbreviations

ABACAS: Algorithm based automatic contiguation of assembled sequences; BLAST: Basic Local Alignment Search Tool; CsCl: Caesium chloride; ICORN: Iterative Correction of Reference Nucleotide; IMAGE: Iterative mapping and assembly for gap elimination; IMS: Immunomagnetic separation; NCBI: National Centre for Biotechnology Information; NGS: Next generation sequencing; PAGIT: Post-assembly genome improvement protocol; (q)PCR: (quantitative) Polymerase chain reaction; RATT: Rapid annotation transfer tool; WGA: Whole genome amplification.
}

\section{Competing interests}

The authors declare that they have no competing interests.

\section{Authors' contributions}

RMC and JAP initiated the study. SJH, GR, RMC and KE developed the DNA preparation methodology, selected clinical samples and prepared
Cryptosporidium DNA. SJSC performed bacterial QPCR. JAP, JA and SJH prepared genomic sequencing libraries. MJH performed NGS. JAP and MTS performed bioinformatic analyses. SJH, RMC, GR, JAP and MTS wrote the manuscript. All authors read and approved the final manuscript.

\section{Authors' information}

$\mathrm{SJH}, \mathrm{GR}, \mathrm{KE}, \mathrm{RMC}$ are Clinical Scientists and RMC is Head of the Cryptosporidium Reference Unit, Public Health Wales, which provides reference services for England and Wales. JAP is Senior Lecturer in Microbial Genomics, MH a Lecturer in Genomics, MTS a Lecturer in Bioinformatics, SJSC a PhD student and JA an MPhil student, all at IBERS, Aberystwyth University.

Submitting author: Dr Justin Alexander Pachebat, Institute of Biological, Environmental and Rural Sciences, Aberystwyth University, Penglais, Aberystwyth. SY23 3FG, UK, +44 (0)1970 62 2347, jip@aber.ac.uk

\section{Acknowledgements}

The research leading to these results has received funding from the European Union Seventh Framework Programme ([FP7/2007-2013] [FP7/2007-2011]) under Grant agreement no: 311846 . JAP and JA were supported by funding from the European Social Fund through the Welsh Government KESS program. The authors thank James Cotton, Wellcome Trust Sanger Institute, for helpful comments on the manuscript.

\section{Author details}

${ }^{1}$ Cryptosporidium Reference Unit, Public Health Wales Microbiology ABM, Singleton Hospital, Sgeti, Swansea, SA2 8QA, United Kingdom. 'Institute of Biological, Environmental \& Rural Sciences, Aberystwyth University, Penglais, Aberystwyth, Ceredigion, SY23 3DA, United Kingdom.

Received: 4 February 2015 Accepted: 31 July 2015

Published online: 29 August 2015

\section{References}

1. Chalmers RM, Davies AP. Mini-review: clinical cryptosporidiosis. Exp Parasitol. 2010;124:138-46.

2. Kotloff KL, Nataro JP, Blackwelder WC, Nasrin D, Farag TH, Panchalingam S, et al. Burden and aetiology of diarrhoeal disease in infants and young children in developing countries (the Global Enteric Multicenter Study, GEMS): a prospective, case-control study. Lancet. 2013;382:209-22.

3. Xu P, Widmer G, Wang Y, Ozaki LS, Alves JM, Serrano MG, et al. The genome of Cryptosporidium hominis. Nature. 2004;431:1107-12.

4. Abrahamsen MS, Templeton TJ, Enomoto S, Abrahante JE, Zhu G, Lancto $\mathrm{CA}$, et al. Complete genome sequence of the apicomplexan. Cryptosporidium parvum. Science. 2004;304:441-5.

5. Guy RA, Payment P, Krull UJ, Horgen PA. Real-Time PCR for Quantification of Giardia and Cryptosporidium in environmental water samples and sewage. Appl Environ Microbiol. 2003;69:5178-85.

6. Widmer G, Lee Y, Hunt Y, Martinelli A, Tolkoff M, Bodi K. Comparative genome analysis of two Cryptosporidium parvum isolates with different host range. Infect Genet Evol. 2012;12:1213-21.

7. Li N, Xiao L, Alderisio K, Elwin K, Cebelinski E, Chalmers R, et al. Subtyping Cryptosporidium ubiquitum, a zoonotic pathogen emerging in humans. Emerg Infect Dis. 2014;20:217-24.

8. Widmer G, Akiyoshi D, Buckholt MA, Feng X, Rich SM, Deary KM, et al. Animal propagation and genomic survey of a genotype 1 isolate of Cryptosporidiurn parvum. Mol Biochem Parasitol. 2000;108:187-97.

9. Baishanbo A, Gargala G, Delaunay A, François A, Ballet JJ, Favennec L. Infectivity of Cryptosporidium hominis and Cryptosporidium parvum genotype 2 isolates in immunosuppressed Mongolian gerbils. Infect Immun. 2005;73:5252-5.

10. Guo Y, Li N, Lysén C, Frace M, Tang K, Sammons S, et al. Isolation and enrichment of Cryptospordiium DNA and verification of DNA purity for whole genome sequencing. J Clin Microbiol. 2015;53(2):641-7.

11. Seth-Smith HMB, Harris SR, Skilton RJ, Radebe FM, Golparian D, Shipitsyna E, et al. Whole-genome sequences of Chlamydia trachomatis directly from clinical samples without culture. Genome Res. 2013;23:855-66.

12. Swain MT, Tsai IJ, Assefa SA, Newbold C, Berriman M, Otto TD. A post-assembly genome-improvement toolkit (PAGIT) to obtain annotated genomes from contigs. Nat Protoc. 2012;7:1260-84.

13. Langmead B, Salzberg S. Fast gapped-read alignment with Bowtie 2. Nat Methods. 2012;9:357-9. 
14. Otto TD, Dillon GP, Degrave WS, Berriman M. RATT: Rapid Annotation Transfer Tool. Nucl Acids Res. 2011;39:e57.

15. Altschul SF, Gish W, Miller W, Myers EW, Lipman DJ. Basic local alignment search tool. J Mol Biol. 1990;215:403-10.

16. Wheeler DL, Barrett T, Benson DA, Bryant SH, Canese K, Chetvernin V, et al. Database resources of the National Center for Biotechnology Information. Nucl Acids Res. 2007;35 suppl 1:D5-D12.

17. Strong WB, Gut J, Nelson RG. Cloning and sequence analysis of a highly polymorphic Cryptosporidium parvum gene encoding a 60-Kilodalton glycoprotein and characterization of Its 15- and 45-kilodalton zoite surface antigen products. Infect Immun. 2000;68:4117-34.

18. Alves M, Xiao L, Sulaiman I, Lal AA, Matos O, Antunes F. Subgenotype analysis of Cryptosporidium isolates from humans, cattle, and zoo ruminants in Portugal. J Clin Microbiol. 2003;41:2744-7.

19. Bouzid M, Chalmers RM, Tyler KM, Elwin K, Hunter PR. Multilocus analysis of Cryptosporidium provides evidence for ecological adaption driving genetically divergent subpopulations. BMC Microbiol. 2010;10:213.

20. Bouzid M, Heavens D, Elwin K, Chalmers RM, Hadfield S, Hunter PR, et al. Whole Genome Amplification (WGA) for archiving and genotyping of clinical isolates of Cryptosporidium species. Parasitology. 2010;137:27-36.

21. Esteban JA, Salas M, Blanco L. Fidelity of $\$ 29$ DNA Polymerase: comparison between protein-primed initiation and DNA polymerization. J Biol Chem. 1993;268:2713-26.

22. Hadfield SJ, Robinson G, Elwin K, Chalmers RM. Detection and differentiation of Cryptosporidium spp. in human clinical samples by use of real-time PCR. J Clin Microbiol. 2011;49:918-24.

23. Tosini F, Drumo R, Elwin K, Chalmers RM, Pozio E, Cacciò SM. The CpA135 gene as a marker to identify Cryptosporidium species infecting humans. Parasitol Int. 2010;59:606-9.

24. Robinson G, Wright S, Elwin K, Hadfield SJ, Katzer F, Bartley PM, et al. Re-description of Cryptosporidium cuniculus Inman and Takeuchi, 1979 (Apicomplexa: Cryptosporidiidae); morphology, biology and phylogeny. Int J Parasitol. 2010:40:1539-48.

25. Elwin K, Hadfield SJ, Robinson G, Chalmers RM. The epidemiology of sporadic human infections with unusual cryptosporidia detected during routine typing in England and Wales, 2000 to 2008. Epidemiol Infect. 2011:140:673-83.

26. Upton SJ. vitro cultivation. In: Fayer R, editor. Cryptosporidium and Cryptosporidiosis. Boca Raton, FL: CRC Press; 1997. p. 181-207.

27. Jones AW, Cameron SJ, Thatcher R, Beecroft MS, Mur LA, Davison G. Effects of bovine colostrum supplementation on upper respiratory illness in active males. Brain Behav Immun. 2014;39:194-203.

28. Kim EJ, Huws SA, Lee MR, Wood JD, Muetzel SM, Wallace RJ, et al. Fish oil increases the duodenal flow of long chain polyunsaturated fatty acids and trans-11 18:1 and decreases 18:0 in steers via changes in the rumen bacterial community. J Nutr. 2008;138:889-96.

29. Le Blancq SM, Khramtsov NV, Zamani F, Upton SJ, Wu TW. Ribosomal RNA gene organization in Cryptosporidium parvum. Mol Biochem Parasitol. 1997;90:463-78.

30. Assefa S, Keane TM, Otto TD, Newbold C, Berriman M. ABACAS: AlgorithmBased Automatic Contiguation of Assembled Sequences. Bioinformatics. 2009:25:1968-9.

31. Tsai IJ, Otto TD, Berriman M. Improving draft assemblies by iterative mapping and assembly of short reads to eliminate gaps. Genome Biol. 2010;11:R41.

32. Otto TD, Sanders M, Berriman M, Newbold C. Iterative Correction of Reference Nucleotides (iCORN) using second generation sequencing technology. Bioinformatics. 2010;26:1704-7.

\section{Submit your next manuscript to BioMed Central and take full advantage of:}

- Convenient online submission

- Thorough peer review

- No space constraints or color figure charges

- Immediate publication on acceptance

- Inclusion in PubMed, CAS, Scopus and Google Scholar

- Research which is freely available for redistribution

Submit your manuscript at www.biomedcentral.com/submit 